\title{
Optical, Thermal, and Mechanical Properties of L-Serine Phosphate, a Semiorganic Enhanced NLO Single Crystal
}

\author{
K. Rajesh, ${ }^{1}$ A. Mani, ${ }^{2}$ V. Thayanithi, ${ }^{2}$ and P. Praveen Kumar ${ }^{2}$ \\ ${ }^{1}$ Department of Physics, Dhanalakshmi College of Engineering, Chennai 601301, India \\ ${ }^{2}$ Department of Physics, Presidency College, Chennai 5, India \\ Correspondence should be addressed to K. Rajesh; krishjayarajesh@gmail.com
}

Received 22 October 2015; Accepted 3 February 2016

Academic Editor: Mark Humphrey

Copyright @ $2016 \mathrm{~K}$. Rajesh et al. This is an open access article distributed under the Creative Commons Attribution License, which permits unrestricted use, distribution, and reproduction in any medium, provided the original work is properly cited.

\begin{abstract}
Single crystals of L-serine phosphate (LSP) were grown by slow evaporation technique. The optical studies reveal the transparency of the crystal in the entire visible region. Grown crystal was subjected to single crystal XRD diffraction technique. Thermal studies of LSP confirm the thermal stability of the crystal and it is stable up to $210^{\circ} \mathrm{C}$. The functional groups and optical behaviour of the crystal were identified from FT-IR and UV-Vis analysis. The crystals were also characterized by microhardness and photoconductivity to determine the mechanical strength and the optical conductivity. Laser damage threshold and nonlinear optical activity of the grown crystal were confirmed by Q-switched Nd : YAG laser beam.
\end{abstract}

\section{Introduction}

The impact of nonlinear optical crystals in science and technology has been recognized recently for several important applications $[1,2]$. This includes sensors, waveguide, transmission, infrared detectors, polarizer, transducers, and image processing; apart from that, the growth of high quality NLO materials for optical switches, optical amplifiers, optical parametric oscillators, and frequency multipliers and mixtures opens a new direction in the field of material science for research. Due to the effectiveness in generating new frequencies from existing laser via harmonic generation, tremendous efforts have been made to identify new materials for such process.

During the past decades, organic and semiorganic materials remain the most widely used crystals for frequency conversion. Organic crystals have a large nonlinear coefficient compared to inorganic crystals. But organic crystals are very sensitive to the presence of intrinsic defects and phonon subsystem $[3,4]$. Inorganic crystals have high mechanical and thermal stability than that of organic crystals $[5,6]$. Semiorganic crystals are those which combine the positive aspects of organic and inorganic materials resulting in desired nonlinear optical properties [7]. Semiorganic crystals have shown potential applications in the field of nonlinear optics.
The importance of nonlinear optics in optical switching, optical memory storage devices, and telecommunication paved the path to identify a suitable and better NLO crystal [8].

Complexes of amino acids with organic and inorganic salts have been identified as promising materials for producing second harmonic generation (SHG) because of their bonding properties with the ions of organic and inorganic salts. Amino acids are playing vital role in the field of nonlinear optics [9]. L-Serine is one of the amino acid family crystals which are easily available in nature $[10,11]$. The molecules of L-serine can combine with anionic, cationic, and overall neutral constituents. The study on growth of L-serine crystals from aqueous solution with hydrochloric acid [12], sodium fluoride [13], formic acid [14], sodium nitrate [15], and acetic acid [16] is reported in recent years.

Orthophosphoric acid is highly polar in nature. It is easily miscible with water. Crystal structure of L-serine phosphate $\left(\mathrm{C}_{3} \mathrm{O}_{3} \mathrm{NH}_{7} \cdot \mathrm{H}_{3} \mathrm{PO}_{4}\right)$ was reported early [17]. In the present investigation, good optical quality L-serine phosphate (LSP) single crystal has been grown from aqueous solution by slow solvent evaporation method. Single crystal X-ray diffraction study has been carried out to confirm the crystalline nature of the grown crystal. FT-IR, UV-Vis-NIR, microhardness, thermal, and photoconductivity studies were carried out for the grown crystal. Second harmonic generation (SHG) and 


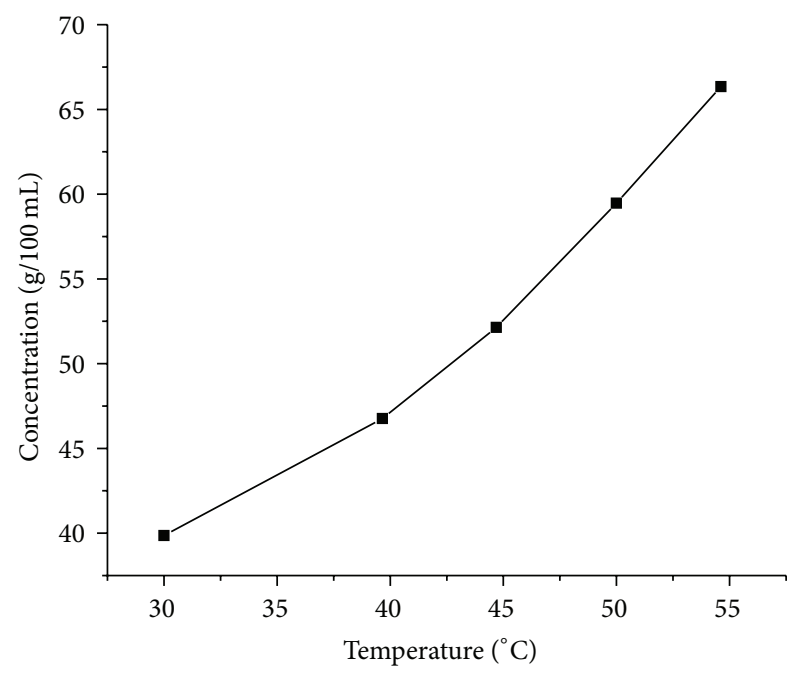

FIGURE 1: Solubility curve of LSP.

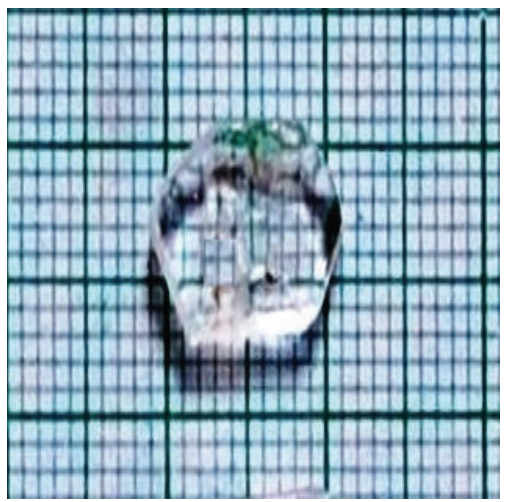

FIGURE 2: Photograph of as-grown LSP crystal.

laser damage threshold (LDT) studies were carried out for the LSP crystal.

\section{Experimental}

L-serine phosphate single crystal was formed in aqueous solution containing L-serine and phosphoric acid in equimolar ratio 1:1 at room temperature. The solution was stirred 9 hours continuously and filtered. The filtered solution is allowed for complete evaporation. The solubility of LSP in deionized water was assessed as a function of temperature in the range of $25^{\circ} \mathrm{C}-50^{\circ} \mathrm{C}$. The solubility was gravimetrically analyzed and was found to increase with increase in temperature which is shown in Figure 1. Seed crystals were obtained in a period of 8 days. The quality of the crystal was improved by successive recrystallization process. Optically good quality single crystal was harvested after 35 days from the day of recrystallization. The grown crystal with dimension $12 \times 8 \times$ $2 \mathrm{~mm}^{3}$ is shown in Figure 2.

\section{Results and Discussion}

3.1. X-Ray Diffraction Study. Single crystal X-ray diffraction studies were carried out using Enraf Nonius CAD-4/MACH
TABLE 1: XRD data of LSP crystal.

\begin{tabular}{lcc}
\hline Cell parameters & Present work & Reported values \\
\hline$a$ & $9.129 \AA$ & $9.134(5) \AA$ \\
$b$ & $9.407 \AA$ & $9.489(5) \AA$ \\
$C$ & $4.626 \AA$ & $4.615(5) \AA$ \\
Crystal system & Monoclinic & Monoclinic \\
$\alpha=\beta$ & $90^{\circ}$ & $90^{\circ}$ \\
$\gamma$ & $98.46^{\circ}$ & $99.54(5)^{\circ}$ \\
Space group & $\mathrm{P} 2_{1}$ & $\mathrm{P} 2_{1}$ \\
\hline
\end{tabular}

3 diffractometer, with MoK $\alpha$ radiation to determine the lattice parameters and space group. The crystal belongs to monoclinic crystal system with the space group $\mathrm{P} 2{ }_{1}$. Cell parameters and space group of the grown crystal are in good agreement with the reported value [17]. XRD data of the grown crystal with reported values are shown in Table 1.

3.2. FT-IR Study. In order to analyze the presence of functional groups in LSP crystal, Fourier transform infrared (FTIR) spectrum was recorded using the Perkin Elmer Infrared spectrophotometer. The fine powder sample of grown L-serine phosphate crystal was subjected to FT-IR analysis. The characteristic absorption peaks are observed in the range from 400 to $4000 \mathrm{~cm}^{-1}$ and are shown in Figure 3 .

The strong absorption peak at $3426 \mathrm{~cm}^{-1}$ indicates the presence of amine in the grown crystal. $\mathrm{NH}_{2}$ plane deformation of primary amine is observed at $1561 \mathrm{~cm}^{-1}$ and $1622 \mathrm{~cm}^{-1}$. The $\mathrm{P}-\mathrm{O}$ stretching frequency and deformation of orthophosphoric acid were identified at the peaks $1047 \mathrm{~cm}^{-1}$ and $496 \mathrm{~cm}^{-1}$, respectively. This confirms the presence of phosphate ion in the grown crystal lattice [18]. The intense peaks at 2860 and $2950 \mathrm{~cm}^{-1}$ are due to $\mathrm{C}-\mathrm{H}$ stretching [19]. The absorption peak at $1470 \mathrm{~cm}^{-1}$ corresponds to $\mathrm{CH}_{3}$ antisymmetric deformation.

\section{Linear and Nonlinear Optical Studies}

4.1. UV-Visible Analysis. UV-Vis-NIR studies give important structural information of a given material because absorption of UV and visible light involves promotion of the electrons in $\pi$ and $n$ orbital from the ground state to higher energy states [20].

The optical absorption spectrum of LSP crystal is shown in Figure 4. The lower cutoff wavelength of the crystal is found as $214 \mathrm{~nm}$. No absorption was found in the visible region of the UV-Vis spectrum. The absence of strong absorption in the entire visible range suggests that the grown LSP crystal is a useful material for the SHG applications [21].

Hence, it is concluded that the grown crystal can be used for optoelectronic applications. The optical absorption coefficient $(\alpha)$ of the crystal was calculated from the UV visible experimental data, using the formula

$$
\alpha=\frac{1}{t} \log \frac{1}{T}
$$




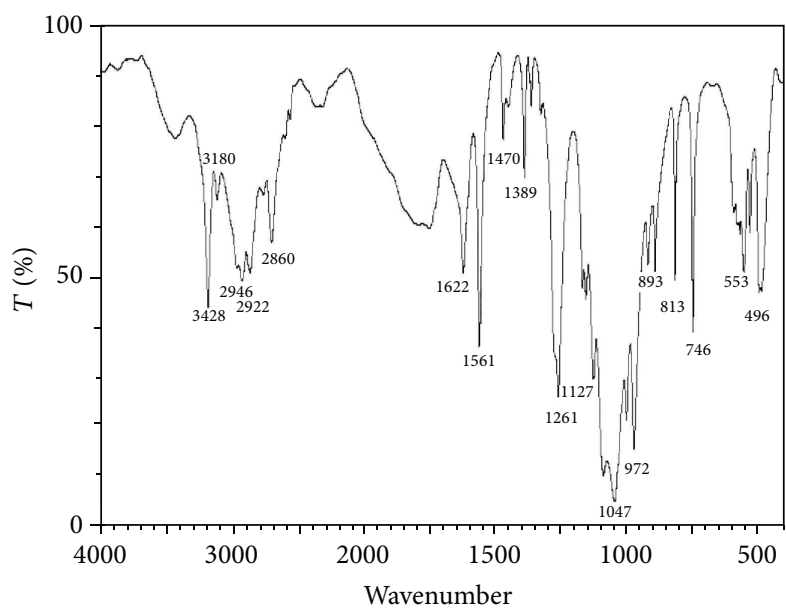

FigURE 3: FT-IR spectrum of LSP crystal.

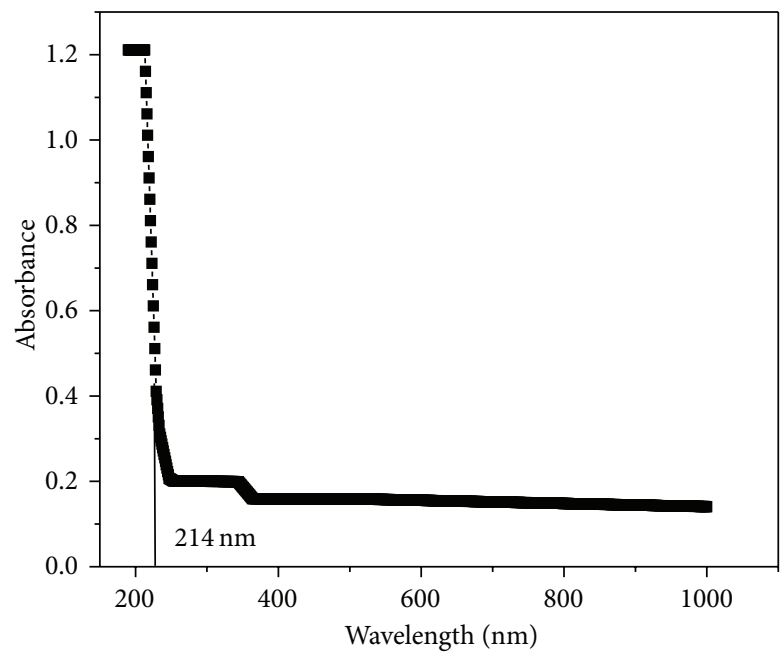

FIGURE 4: UV-Vis spectrum of LSP crystal.

where $t$ is the thickness of the crystal and $T$ is thetransmittance of the crystal. The optical band gap energy of the crystal can be calculated from Tauc's plot. The optical energy gap (Eg) of the grown LSP crystal was calculated as $5.76 \mathrm{eV}$ from Tauc's plot of $h v$ versus $(\alpha h v)^{2}$ which is shown in Figure 5.

4.2. Nonlinear Optical (NLO) Studies. Kurtz powder technique was performed on LSP crystal to confirm the second harmonic generation efficiency [22]. Potassium dihydrogen phosphate (KDP) crystal was used as a reference material for second harmonic generation test. The output SHG signal of $79.7 \mathrm{mV}$ for the LSP crystal was obtained for an input energy of $5 \mathrm{~mJ} /$ pulse, whereas the KDP crystal gave an output of $27.6 \mathrm{mV}$ for the same input signal. Thus the SHG efficiency of the LSP crystal is 2.9 times greater than KDP crystal.

4.3. Laser Damage Threshold Test. LDT measurement of the LSP crystal has been carried out using a Q-switched Nd: YAG laser beam of wavelength $1064 \mathrm{~nm}$ with the pulse width of $10 \mathrm{~ns}$. The repetition rate of the LDT measurement is $10 \mathrm{~Hz}$.

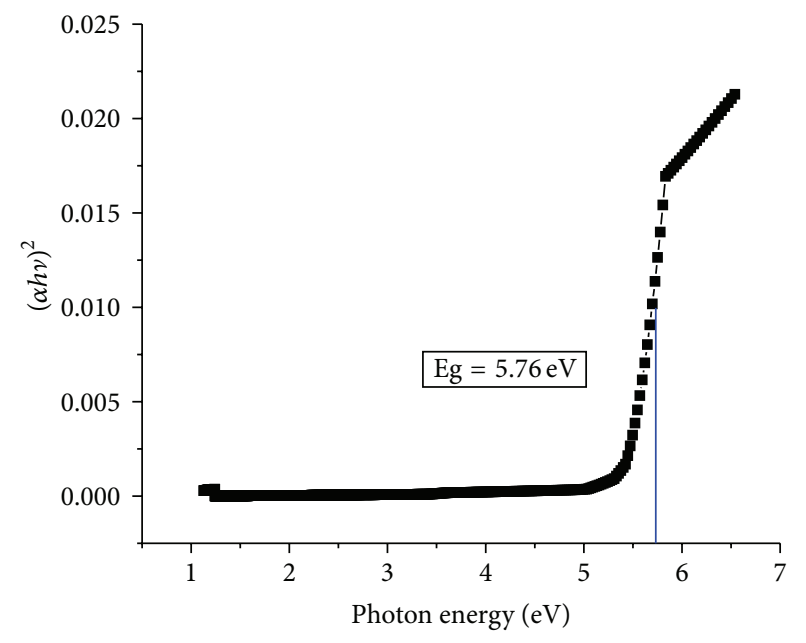

FIGURE 5: Optical band gap energy of LSP.

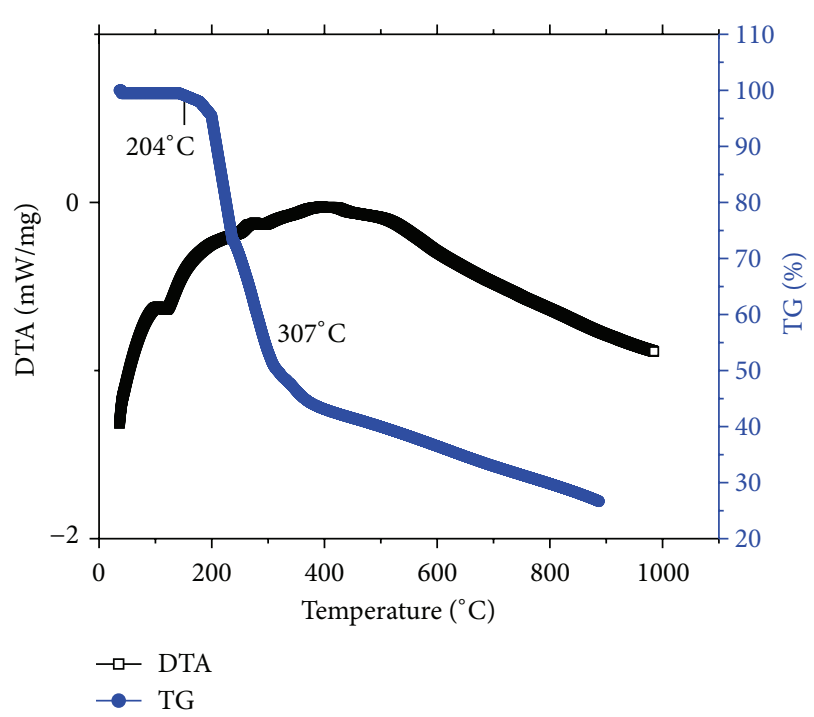

FIGURE 6: TGA and DTA traces of LSP crystal.

The laser beam of focal length $1 \mathrm{~mm}$ is focused on the sample of $0.7 \mathrm{~mm}$. The LDT value of the grown crystal is found to be $5.27 \mathrm{GW} / \mathrm{cm}^{2}$.

Hence, the crystal has a high LDT value; it is observed that L-serine phosphate crystal can be used for high power frequency conversion application [23].

4.4. Thermal Analysis. Thermogravimetric analysis (TGA) and differential thermal analysis (DTA) of L-serine phosphate single crystal were carried out using a NETZSCH STA $409^{\circ} \mathrm{C}$ thermal analyzer. The sample was heated in the temperature ranges between $10^{\circ} \mathrm{C}$ and $1000^{\circ} \mathrm{C}$ at a heating rate of $10 \mathrm{~K} / \mathrm{min}$ in nitrogen atmosphere.

The TGA and DTA traces of LSP crystal are shown in Figure 6. From the plot it is found that the first stage of decomposition of the grown crystal starts at $204^{\circ} \mathrm{C}$ and the crystal starts to decompose further in weight due to the liberation of volatile gases and compounds. It is concluded 


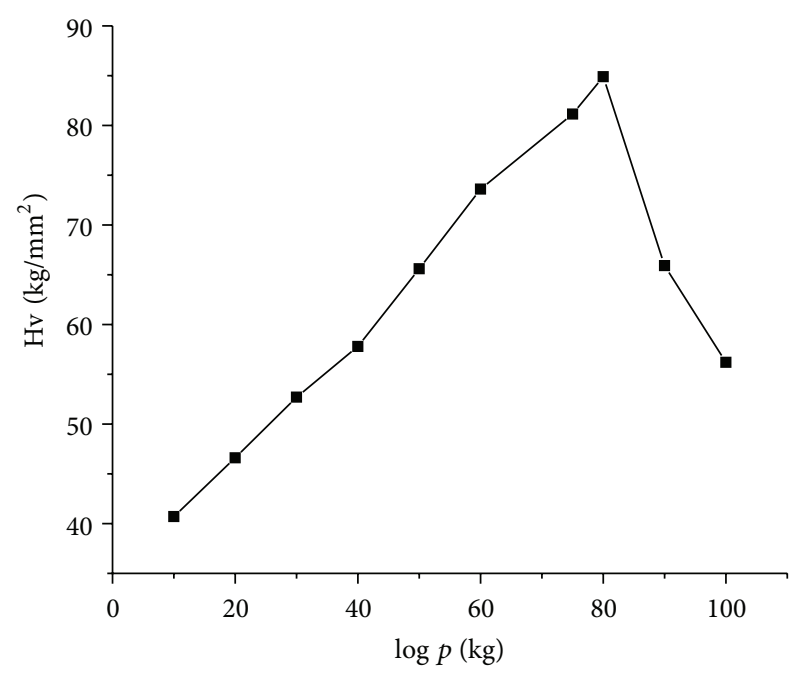

FIgURE 7: Hardness number plot of LSP.

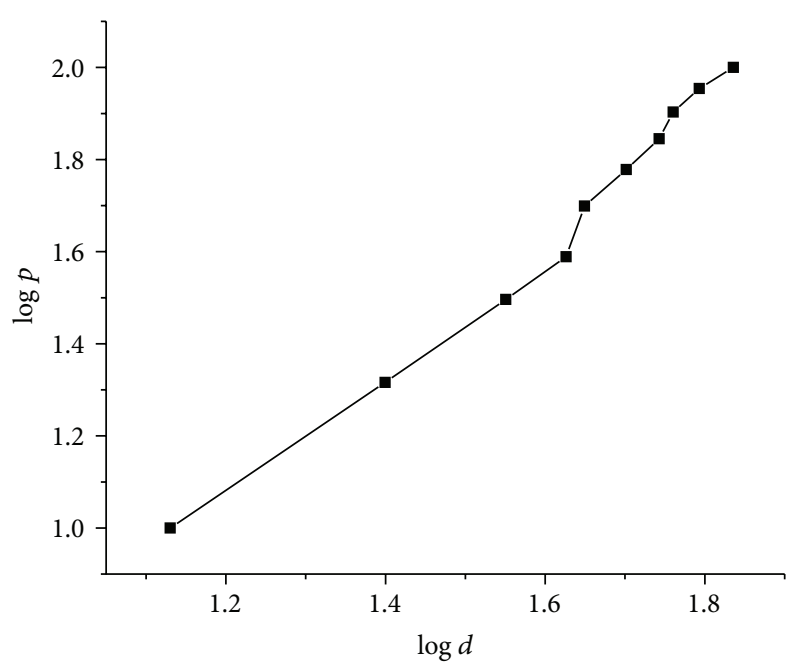

Figure 8: Plot of indentation $(d)$ versus load $(p)$.

that the LSP crystal is thermally stable up to $204^{\circ} \mathrm{C}$. Almost $50 \%$ weight of the starting material is lost around $307^{\circ} \mathrm{C}$. Further the crystal is fully decomposed around $900^{\circ} \mathrm{C}$.

4.5. Vickers Microhardness Study. Mechanical stability of the crystal was found using Vickers microhardness tester. To get accurate results of hardness of the grown crystal, indentations were made on the LSP crystals with applied load ranging from $10 \mathrm{~g}$ to $100 \mathrm{~g}$. The values of Vickers microhardness at different loads were calculated and a graph was drawn between hardness number and the applied load and is shown in Figure 7.

The hardness number was found to increase with the applied load up to $80 \mathrm{~g}$ and then decreases gradually due to the microcracks developed in the crystal.

The value of working hardness coefficient of the material was calculated from the slope of the plot between $\log p$ and $\log d$ (Figure 8 ) and it is found to be 1.17. According to

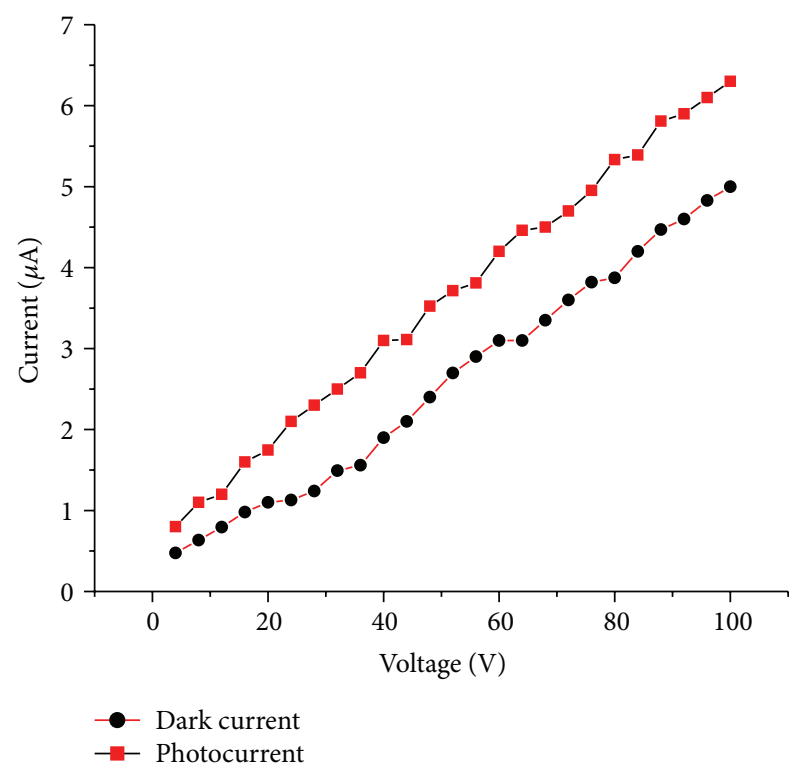

FIGURE 9: Photoconductivity plot of LSP.

Onitsch, $n$ lies between 1 and 1.6 for hard materials, and $n$ is greater than 1.6 for soft materials [24]. Hence, it is concluded that the LSP crystal belongs to hard material category.

4.6. Photoconductivity Study. Photoconductivity studies were carried out for the LSP crystal using Keithley 485 Picoammeter at room temperature. The dark current $\left(I_{d}\right)$ of the sample was measured using DC power supply and picoammeter. The power from the halogen lamp incident on the crystal is $100 \mathrm{~W}$. Photocurrent of the sample was measured using halogen lamp containing iodine vapor. The light from halogen lamp is focused on the material using convex and the photocurrent is measured. DC supply is increased step by step from $10 \mathrm{~V}$ to $100 \mathrm{~V}$ and the photocurrent $\left(I_{p}\right)$ was measured.

Figure 9 shows the variation of photocurrent and dark current as a function of applied field. It is observed from the plot that the dark current $\left(I_{d}\right)$ and photocurrent $\left(I_{p}\right)$ of the sample increase linearly with the applied field. The photocurrent is always higher than the dark current. This phenomenon is known as positive photoconductivity [25].

\section{Conclusion}

A potential semiorganic nonlinear optical single crystal of Lserine phosphate was grown by slow evaporation technique. Single crystal X-ray diffraction study confirms that the grown crystal belongs to monoclinic system with space group $\mathrm{P} 2_{1}$.

FT-IR studies confirm the various functional groups present in the crystal and they give the evident of anharmonic phonons in the vibrational spectrum of the crystal. These anharmonic phonons are responsible for nonlinearity in noncentrosymmetric crystals. The grown LSP has a wide transparency window in the entire visible region with a lower cutoff wavelength of $214 \mathrm{~nm}$ thus confirming the suitability 
of this material for various optoelectronic and photoelectric applications. The hardness of the material indicates that the material belongs to hard material category, which can be useful for the high frequency conversion devices. Thermal studies revealed that LSP crystal is thermally stable up to $204^{\circ} \mathrm{C}$. Photoconductivity studies show that the material exhibits positive photoconductivity. Positive photoconductivity is achieved at anion interstitials. The powder SHG efficiency of LSP crystal is about 3 times that of KDP. It is concluded that LSP crystal is a suitable material for NLO applications with higher efficiency. Laser damage threshold value of the crystal is calculated from the experimental data and it is found to be $5.27 \mathrm{GW} / \mathrm{cm}^{2}$. It is concluded that the grown LSP crystal can be used in potential applications in the field of optoelectronic sensors.

\section{Conflict of Interests}

The authors declare that there is no conflict of interests regarding the publication of this paper.

\section{References}

[1] P. N. Prasad and D. J. Williams, Introduction of Nonlinear Optical Effects in Molecular and Polymers, Wiley-Interscience, New York, NY, USA, 1991.

[2] Ch. Bosshard, M. Bösch, I. Liakatas, M. Jäger, and P. Günter, "Second-order nonlinear optical organic materials: recent developments," in Nonlinear Optical Effects and Materials, vol. 72 of Springer Series in Optical Sciences, pp. 163-299, Springer, Berlin, Germany, 2000.

[3] V. Krishnakumar, G. Eazhilarasi, R. Nagalakshmi, M. Piasecki, I. V. Kityk, and P. Bragiel, "Field-induced non-linear optical features of p-aminoazobenzene crystals," The European Physical Journal: Applied Physics, vol. 42, no. 3, pp. 263-267, 2008.

[4] V. Krishnakumar, S. Kalyanaraman, M. Piasecki, I. V. Kityk, and P. Bragiel, "Photoinduced second harmonic generation studies on Tris(thiourea)copper(I) perchlorate $\mathrm{Cu}\left(\mathrm{SC}\left(\mathrm{NH}_{2}\right)_{2}\right)_{3}\left(\mathrm{ClO}_{4}\right)$," Journal of Raman Spectroscopy, vol. 39, no. 10, pp. 1450-1454, 2008.

[5] V. G. Dimitrieve, G. G. Gurzodyan, and D. N. Nikogosyan, Nonlinear Optical Crystals, Springer, Berlin, Germany, 1991.

[6] V. J. Williams, Nonlinear Optical Properties of Organic and Polymeric Materials, American Chemical Society, Washington, DC, USA, 1993.

[7] S. Natarajan, G. Shanmugam, and S. A. M. B. Dhas, "Growth and characterization of a new semi organic NLO material: Ltyrosine hydrochloride," Crystal Research and Technology, vol. 43, no. 5, pp. 561-564, 2008.

[8] D. S. Chemla and J. Zyss, Nonlinear Optical Properties of Organic Molecules and Crystals, 1-2, Academic Press, New York, NY, USA, 1987.

[9] R. Ramesh Babu, N. Vijayan, R. Gopalakrishnan, and P. Ramasamy, "Growth and characterization of L-lysine monohydrochloride dihydrate (L-LMHCl) single crystal," Crystal Research and Technology, vol. 41, no. 4, pp. 405-410, 2006.

[10] S. Moitra and T. Kar, "Second harmonic generation of a new nonlinear optical material l-valine hydrobromide," Journal of Crystal Growth, vol. 310, no. 21, pp. 4539-4543, 2008.
[11] T. U. Devi, N. Lawrence, R. R. Babu, and K. Ramamurthi, "Growth and characterization of L-prolinium picrate single crystal: a promising NLO crystal," Journal of Crystal Growth, vol. 310, no. 1, pp. 116-123, 2008.

[12] M. Parthasarathy, M. Anantharaja, and R. Gopalakrishnan, "Growth and characterization of large single crystals of L-serine methyl ester hydrochloride," Journal of Crystal Growth, vol. 340, no. 1, pp. 118-122, 2012.

[13] G. R. Dillip, C. M. Reddy, and B. D. P. Raju, "Growth and characterization of non-linear optical material," Journal of Minerals and Materials Characterization and Engineering, vol. 10, no. 12, pp. 1103-1110, 2011.

[14] P. Krishnan, K. Gayathri, and G. Anbalagan, "Growth and characterization of L-serine formate nonlinear optical single crystal," AIP Conference Proceedings, vol. 1512, no. 1, pp. 906907, 2013.

[15] S. D. Zulifiqar Ali Ahamed, G. R. Dillip, L. Manoj, P. Raghavaiah, B. Raghavaiah Deva, and P. Raju, "Growth and characterization of a new NLO material: L-serine sodium nitrate," Photonics Letters of Poland, vol. 2, no. 4, pp. 183-185, 2010.

[16] K. Rajesh, P. P. Kumar, A. Zamara, and A. Thirugnanam, "Growth, optical, mechanical and electrical properties of Lserine acetate: a promising semiorganic nonlinear optical crystal," in Proceedings of the International Conference on Recent Trends in Applied Physics and Material Science (RAM '13), vol. 1536 of AIP Conference Proceedings, pp. 759-760, Bikaner, India, February 2013.

[17] Yu. I. Smolin, A. E. Lapshin, and G. A. Pankova, "Crystal structure of $L$-serine phosphate," Crystallography Reports, vol. 50, no. 1, pp. 58-60, 2005.

[18] J. R. Lehr, E. T. Brown, A. W. Frazier, J. P. Smith, and R. D. Thrasher, Crystallographic Properties of Fertilizer Compounds, Chemical Engineering Bulletin, National Fertilizer Development Center, Muscle Shoals, Ala, USA, 1967.

[19] D. W. Mayo, F. A. Miller, and R. W. Hannah, Course Notes on the Interpretation of Infrared and Raman Spectra, John Wiley \& Sons, Hoboken, NJ, USA, 2003.

[20] M. Prakash, D. Geetha, and M. Lydia Caroline, "Crystal growth and characterization of L-phenylalaninium trichloroacetate-a new organic nonlinear optical material," Physica B: Condensed Matter, vol. 406, no. 13, pp. 2621-2625, 2011.

[21] V. Venkataramanan, S. Maheswaran, J. N. Sherwood, and H. L. Bhat, "Crystal growth and physical characterization of the semiorganic bis(thiourea) cadmium chloride," Journal of Crystal Growth, vol. 179, no. 3-4, pp. 605-610, 1997.

[22] S. K. Kurtz and T. T. Perry, "A powder technique for the evaluation of nonlinear optical materials," Journal of Applied Physics, vol. 39, article 3798, 1968.

[23] N. Vijayan, G. Bhagavannarayana, T. Kanagasekaran, R. R. Babu, R. Gopalakrishnan, and P. Ramasamy, "Crystallization of benzimidazole by solution growth method and its characterization," Crystal Research and Technology, vol. 41, no. 8, pp. 784789, 2006.

[24] E. M. Onitsch, "The present status of testing the hardness of materials," Microscope, vol. 95, pp. 12-14, 1950.

[25] R. H. Bube, Photoconductivity of Solids, John Wiley \& Sons, New York, NY, USA, 1981. 

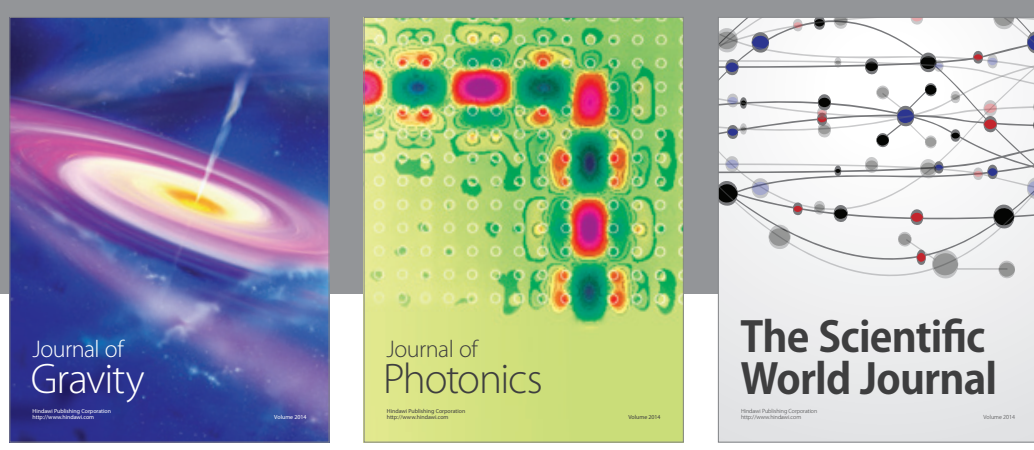

The Scientific World Journal
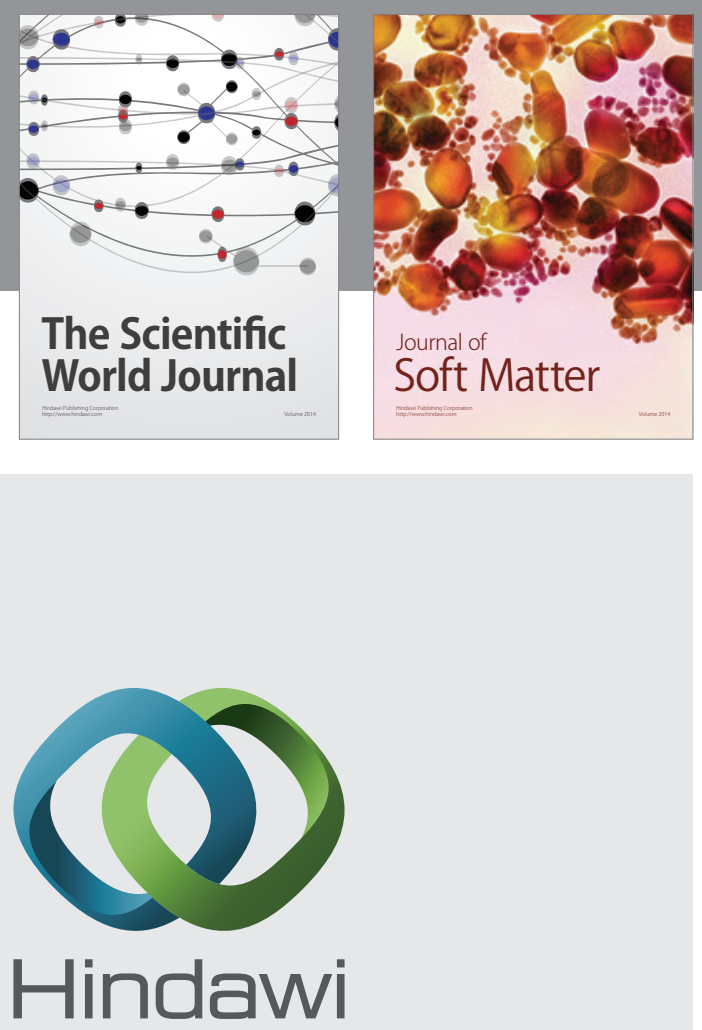

Submit your manuscripts at

http://www.hindawi.com

nternational Journal of

Statistical Mechanics
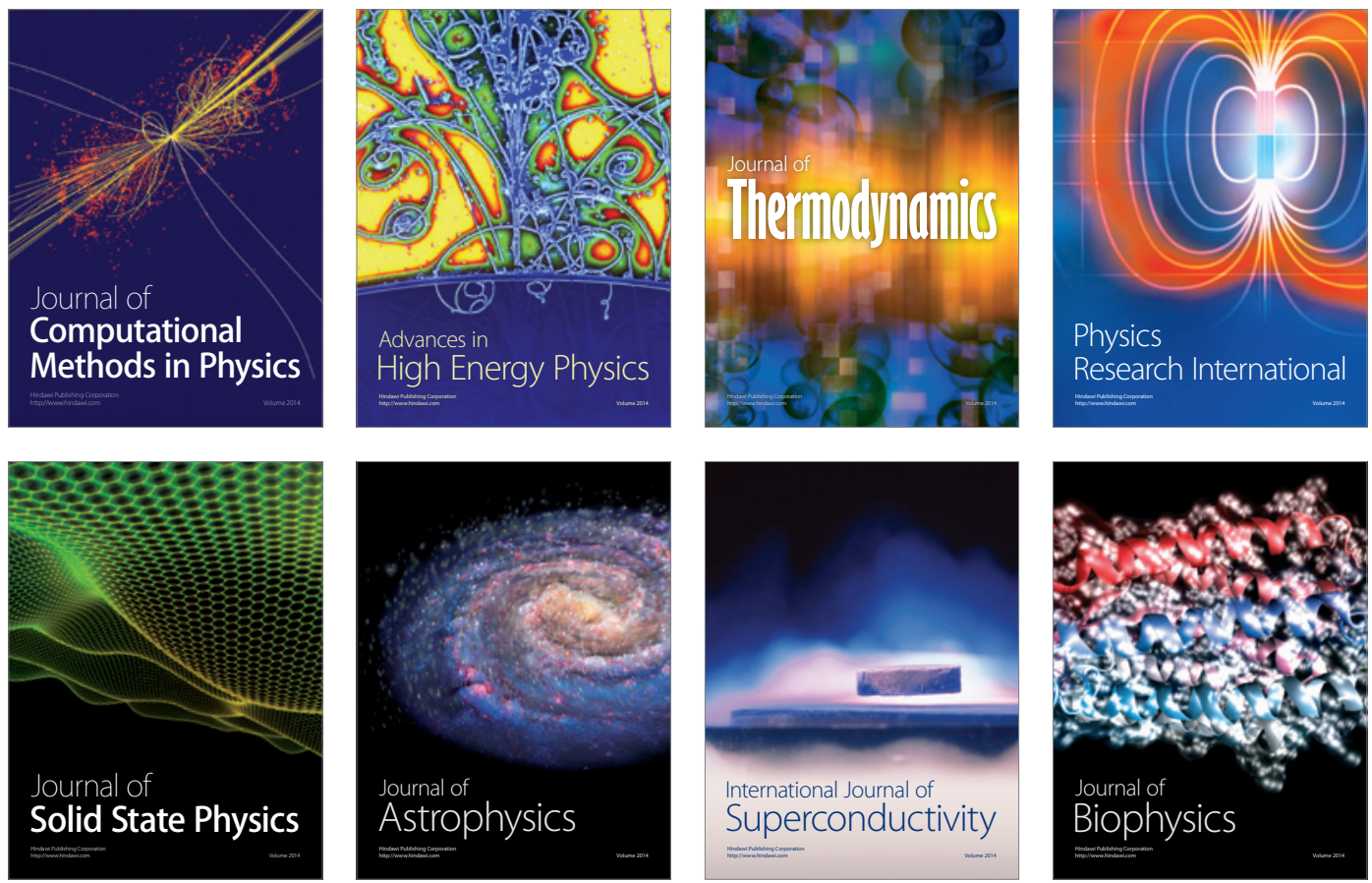
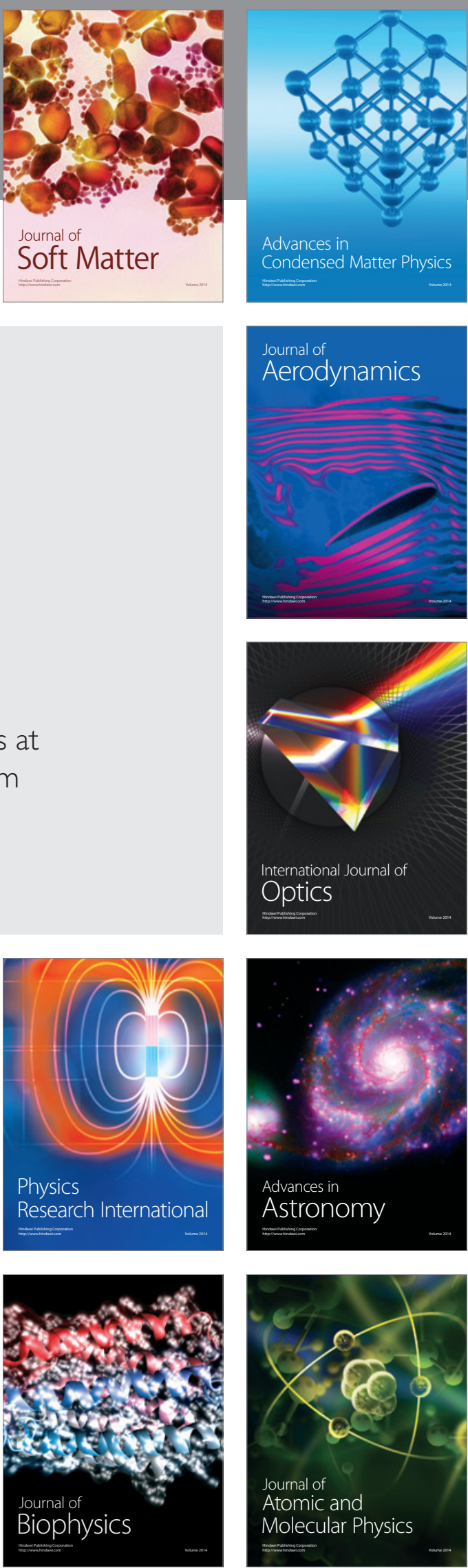